\title{
Increased Zooplankton Behavioral Stress in Response to Short-Term Exposure to Hydrocarbon Contamination
}

\author{
Laurent Seuront*, ${ }^{* 1,2}$ and Sophie C. Leterme ${ }^{1}$ \\ ${ }^{1}$ School of Biological Sciences, Flinders University, South Australia, Australia; ${ }^{2}$ Laboratoire d'Océanologie et de Géos- \\ ciences, CNRS UMR 8187, Université des Sciences et Technologies de Lille-Lille 1, Wimereux, France
}

\begin{abstract}
The swimming behavior of the calanoid copepod Centropages hamatus is used as a very sensitive real-time screening tool to assess hydrocarbon contamination in marine waters. A behavioral stress index based on the complexity of swimming sequences is suggested as a potential tool to critically assess behavioral responses to natural and anthropogenic forcing in the marine environment.
\end{abstract}

\section{INTRODUCTION}

Massive crude oil spills such as Torey Canyon (1967), Amoco Cadiz (1978), Ixtoc-I (1979-80), Exxon Valdez (1989), Sea Empress (1996), Erika (1999) and Prestige (2002) are a major source of polycyclic aromatic hydrocarbons (PAHs) in estuarine and coastal waters [1]. However, leaking from ships, petroleum transport, refining, intentioned spills, are more pernicious, but equally important, sources of PAHs in the ocean [1-2], especially in coastal and shelf waters [3-6].

The effects of PAHs contamination on marine planktonic organisms have been studied extensively in the laboratory and in the field, and a variety of reactive changes have been found in relation to incidental oil spills for a range of plankton species, manifested as alterations of biomass, abundance, and ecophysiological effects. Mesocosm experiments have yielded important information on the direct toxic effects on phyto- and zooplankton assemblages as well as the indirect effects on food-web interactions [7-11]. In these studies, artificial oil addition often increased the abundance of bacterioplankton and phagotrophic protists such as choanoflagellates and tintinnid ciliates, suggesting an enhanced carbon transfer from bacterial production to higher-order organisms in the microbial loop. Concurrently, the presence of oil readily depresses growth and photosynthesis of phytoplankton in pure cultures and natural aquatic environments [12-13], and most zooplankton in acute and chronic exposure experiments are highly vulnerable to hydrocarbons [14]. To date, the few studies regarding sub-lethal effects of hydrocarbons on copepods show, however, a very variable scenario depending on the chemicals used, their concentrations, and time of exposure, including anomalous metabolism [15-16], decreased or inhibited feeding [17-20], increased mortality [21], reduction in egg production [22], hatching rates [19], clutch size [23].

At low concentration and for short time exposure, hydrocarbons did not have any significant effect on feeding and egg production [17-19,24]. Decreases in egg production are observed, however, after long exposures to low hydrocarbon

*Address correspondence to this author at the School of Biological Sciences, Flinders University, GPO Box 2100, Adelaide SA 5001, South Australia, Australia;

E-mail: Laurent.Seuront@flinders.edu.au concentrations [22], indicating detrimental cumulative effects unidentifiable under short-term incubations. While PAHs concentrations can reach dramatic concentrations up to $600 \mu \mathrm{g}^{-1}$ in the North Sea and Sargasso Sea [25-26] and $10980 \mu \mathrm{g} \mathrm{l}^{-1}$ in the Adriatic Sea [27], the 'natural' concentrations of PAHs typically range between 1 and $100 \mu \mathrm{g}^{-1}$ [4,6,28-29]. The ability to assess rapidly any increase in the background concentration of PAHs related to e.g. incidental, localized oil spills is then critical to anticipate their pernicious cumulative effects on copepod biology and ecology.

Since swimming and feeding are intertwined in most copepod species, any disruption of copepod swimming is predicted to have detrimental consequences to copepod biology and ecology. Measurements of an organism's behavior following contaminant exposure may then provide a better understanding of the likely environmental consequences of toxic contamination than lethal effects, especially if behavior is disrupted at environmentally-realistic toxicant concentrations. Despite the few attempts to use the swimming behavior of the freshwater cladoceran Daphnia sp. as an indicator of exposure to toxic chemicals [30-34] and the increasing use of animals as an integrated measure of sub-lethal pollutant effects [35], similar information for marine invertebrates is still very limited [36]. In particular, no attempts have been made to assess the effects of hydrocarbons on copepod behavior, despite an impressive body of literature devoted to their behavioral ecology [37-40].

In this context, we assessed the potential for copepod swimming behavior to be used as an index of anthropogenic pollution. In particular, the effects of short-term exposure to 'natural' and extreme naphthalene (the most abundant hydrocarbon dissolved in oil contaminated waters) concentration are presented and analyzed.

\section{ZOOPLANKTON COLLECTION AND ACCLIMA- TION}

Copepods were collected in the coastal waters of the eastern English Channel using a WP2 net $(200-\mu \mathrm{m}$ mesh size) with close cod end horizontally towed between 0 to 5 $\mathrm{m}$. Specimens were gently diluted in 30-litre isotherm tanks using in situ seawater ( $S=34$ PSU) and transported to the laboratory, where Centropages hamatus adult females were sorted by pipette under a dissecting microscope and acclimated for 12 hours in a 2-litre beaker containing fresh in situ 
seawater vacuum filtered through Whatman GF/C glass-fiber filters (porosity $0.45 \mu \mathrm{m}$ ) prior to the behavioral experiments. All subsequent handling of animals was done at $18^{\circ} \mathrm{C}$ in a temperature controlled room.

\section{TOXICITY TEST}

The polycyclic aromatic hydrocarbon tested was the naphthalene as it has been widely used in toxicological assays involving copepods $[17,22,24,41-42]$ and is one of the most abundant hydrocarbons dissolved in oil contaminated waters [41]. Naphthalene ( $96 \%$ purity, Sigma-Aldrich, St Louis, USA) stock solutions were prepared using acetone as a carrier (HPLC grade, $0.5 \mathrm{ml} \mathrm{l}^{-1}$ ). Naphthalene stock solutions were transferred into the behavioral container and diluted with GF/C filtered (porosity $0.45 \mu \mathrm{m}$ ) in situ seawater at 50,100, 500, 1000, 2500, 5000 and $10000 \mu \mathrm{g} \mathrm{l^{-1 }}$ to assess the effect of 'natural' (1-100 $\mu \mathrm{g} \mathrm{l}^{-1}$; [3-6]) and extreme (up to $10980 \mu \mathrm{g} \mathrm{l}^{-1}$; [27]) PAHs concentrations encountered in the ocean. In addition to the toxicity experiments, two controls were considered with $\left(0.5 \mathrm{ml} \mathrm{l}^{-1}\right.$ in GF/C filtered in situ seawater) and without (GF/C filtered in situ seawater) acetone to assess the potential effect of acetone on $C$. hamatus swimming behavior.

\section{BEHAVIORAL OVERVATIONS AND IMAGE ANALYSIS}

Experiments were conducted for each naphthalene concentration with adult females in a temperature controlled dark room $\left(18^{\circ} \mathrm{C}\right)$ to assess their behavioral properties in relation to short-term exposure to naphthalene contamination. Prior to each experiment, ten females $1.31 \pm 0.05 \mathrm{~mm}$ (cephalothorax length, mean $\pm \mathrm{SD}$ ) were randomly selected from the females stock, transferred in the experimental filming set-up filled up (a cubical 3.375-1 glass container, $15 \times$ $15 \times 15 \mathrm{~cm}$ ) with the test solutions and allowed to acclimatize for $10 \mathrm{~min}$ [39]. All the experiments were conducted with aerated (100\% air saturation) fresh in situ seawater (salinity $S=34 \mathrm{PSU}$ and $\mathrm{pH}=7.5$ ), in the dark and at night to avoid any potential behavioral artifact related to endogenous swimming rhythms [39]. The three-dimensional trajectories of the copepod were recorded at a rate of 25 frame $\mathrm{s}^{-1}$ using two orthogonal, synchronized infrared digital cameras (DV Sony DCR-PC120E) facing the experimental container. The various components of the set-up were adjusted so that the copepods were adequately resolved and in focus. To avoid any bias related to phototropism, the only light source was provided by six arrays of 72 infrared light emitting diodes (LEDs), each mounted on a printed circuit board about the size of a business card (i.e. $9.3 \mathrm{~cm}$ long and $4.9 \mathrm{~cm}$ wide) connected to a 12 volts DC power supply. For each experimental condition, 10 individual females were recorded swimming for $20 \mathrm{~min}$, after which valid video clips were identified for analysis. Valid video clips consisted of pathways in which the animals were swimming freely, at least two body lengths away from any chamber's walls or the surface of the water. Between 8 and 20 swimming paths were considered for each female. Duration of individual observations varied, and swimming paths ranged between $39 \mathrm{~s}$ and 3 min. Selected video clips were captured (DVgate Plus, 25 frames $\mathrm{s}^{-1}$ ) as AVI movies and converted into QuickTime TM movies (QuickTime Pro), after which the $x, y$ and $z$ coordinates of swimming pathways were automatically ex- tracted and subsequently combined into a 3D picture using LabTrack software (DiMedia, Kvistgård, Denmark). The time step was always $0.04 \mathrm{~s}$, and output sequences of $(x, y, z)$ coordinates were subsequently used to characterize the motility.

\section{BEHAVIORAL ANALYSIS}

Free-swimming Centropages hamatus pattern typically exhibits swimming bouts separated by breaking events during which they eventually sink tail pointed upward. As a consequence, the impact of naphthalene on the swimming behavior of $C$. hamatus was assessed through potential changes in (i) swimming speed $\left(\mathrm{mm} \mathrm{s}^{-1}\right)$, sinking speed $(\mathrm{mm}$ $\mathrm{s}^{-1}$ ), and (ii) percentage of time allocated to swimming (\%).

By analogy with self-organized critical systems that build-up stress and then release the stress in intermittent pulses, the level of stress arising from each experimental conditions was described by a power-law that states that the cumulative probability distribution function of move duration $T$ greater than a determined duration $t$ follows [43-44] $P(t \leq T)=k t^{-\phi}$ where $k$ is a constant and $\phi$ the scaling exponent describing the distribution. The exponent $\phi$ should decline under stress [45-46], and would be referred to as a 'stress exponent' hereafter. The scaling exponent $\phi$ was estimated as the slope of $N(t \leq T)$ versus $t$ in log-log plots. Linear regression on the log-transformed data was used instead of nonlinear regression on the raw data as the residual error will be distributed as a quadratic and the minimum error is not guaranteed. This is not the case with nonlinear regression [43]. Finally, because an objective criterion is needed for deciding upon the appropriate range of $t$ values to be included in the regression, we used $N(t \leq T)$ and $t$ values which maximized the coefficient of determination and minimized the total sum of the squared residuals for the regression [43].

The distribution of the behavioral parameters were significantly non-Normal (Kolmogorov-Smirnov test, $\mathrm{p}<0.01$ ). Non-parametric statistics were then used throughout this work. Multiple comparisons between experimental conditions were conducted using the Kruskal-Wallis test, and a subsequent multiple comparison procedure based on the Tukey test was used to identify distinct groups of measurements [47].

\section{NAPHATHALENE CONTAMINATION AND SWIM- MING BEHAVIOR}

C. hamatus adult females typically swam in helical loops (Fig. 1), and no differences were visually perceptible between uncontaminated control seawater (Fig. 1a) and naphthalene contaminated seawater (Fig. 1b). The swimming speed $(6.51 \pm 0.04 \mathrm{~mm})$, the sinking speed $(1.52 \pm 0.05 \mathrm{~mm})$ and the time spent swimming $(66 \pm 2 \%)$ were not significantly different for the control experiments with and without acetone $(p>0.05)$. No significant differences in swimming and sinking speeds were found between $C$. hamatus considered in uncontaminated and naphthalene contaminated seawater ( $>0.05$ ). The time spent swimming exhibits, however, a significant linear increase $(\mathrm{p}<0.01)$ with naphthalene concentration from 66 to $81 \%$. This indicates an increase in swimming activity under conditions of naphthalene contamination, and is consistent with previous observations showing an increased in the foraging activity of $C$. hamatus individuals 
exposed to micro-scale turbulence [48-49], a ubiquitous natural stressor of the marine environment.

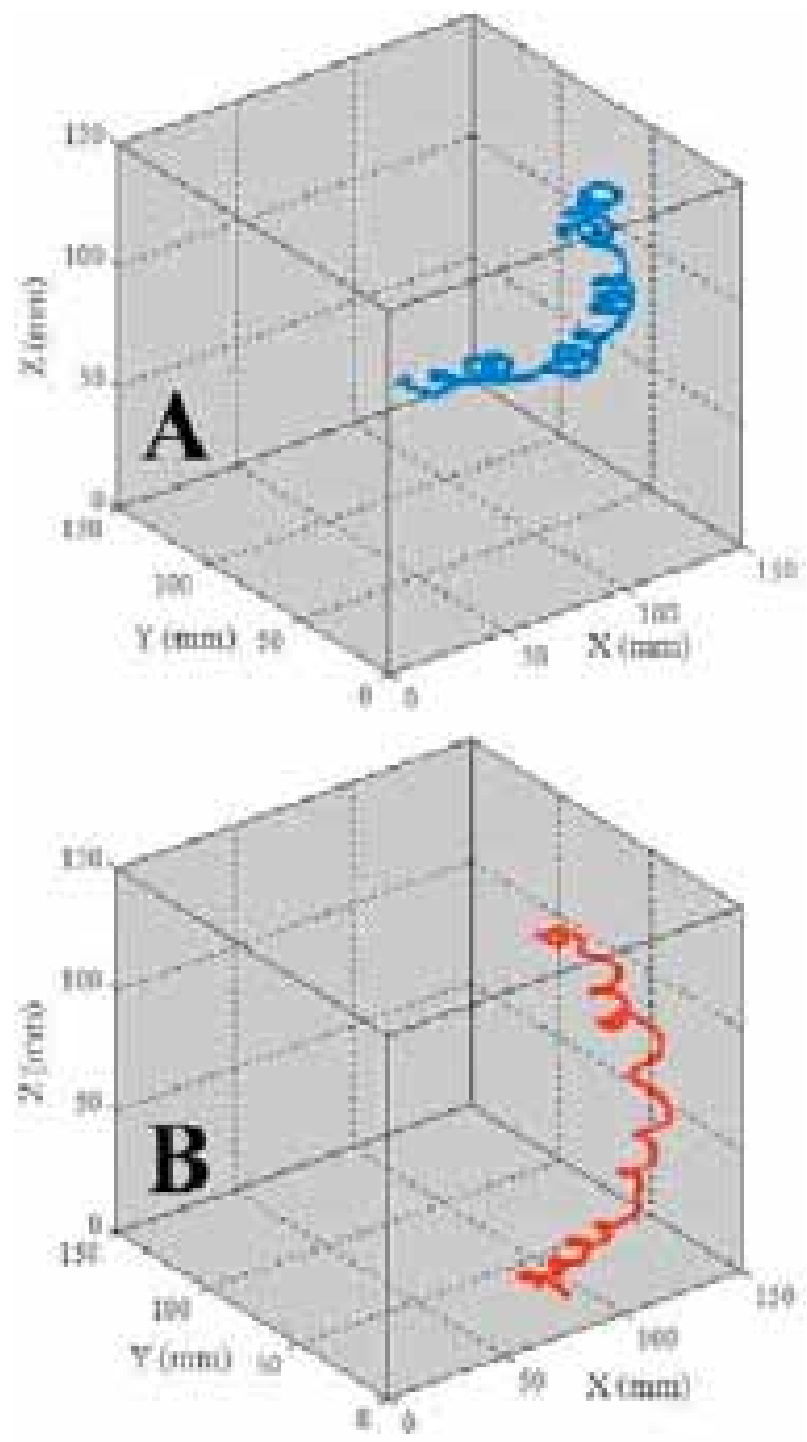

Fig. (1). Examples of the swimming behavior of the calanoid copepod $C$. hamatus in uncontaminated seawater (A) and in naphthalene contaminated $\left(1000 \mu \mathrm{g} \mathrm{l}^{-1}\right)$ seawater $(\mathbf{B})$.

The stress exponent $\phi$ did not significantly differ between the control experiments conducted with and without acetone (F-test, $\mathrm{p}>0.05)$. In contrast, the values of $\phi$ were significantly different for uncontaminated and naphthalene contaminated seawater $(p<0.05$, Fig. 2). While $\phi$ values were consistently significantly smaller $(\mathrm{p}<0.05)$ for the naphthalene contaminated seawater than for the uncontaminated controls, they exhibit a highly significant $(\mathrm{p}<0.01)$ powerlaw decay with naphthalene concentrations $C$ as $\phi=$ $1.94 C^{-0.11}$ (Fig. 3). This clearly indicates an increase in behavioral stress with increasing naphthalene concentration.

\section{BEHAVIORAL COMPLEXITY AND STRESS}

In response to stress, organisms typically increase their metabolic rate and energy intake [50-51] and perform a series of compensatory responses to improve the probability of survival, involving the endocrine system and behavior [52]. As a consequence, a stressed animal will reduce the complexity of behavioral display [53-55]. The subsequent change in pattern distribution of behavior sequences is likely to be related to the underlying dynamics of physiological components and can be used to detect the level of stress under different environmental conditions. This is consistent with the observed change in the complexity of behavior sequence with naphthalene concentration that illustrates the influence of stress on temporal patterns. The fact that fluctuations of behavior sequences tended to be more complex under nonstressful situations (i.e. no naphthalene or low naphthalene concentration) can be thought as an adaptive strategy that allows the organisms to exchange more information with the surroundings. During stressful situations (i.e. high naphthalene concentrations) there is not enough energy available and the complexity of behavior sequences are reduced [56-57].

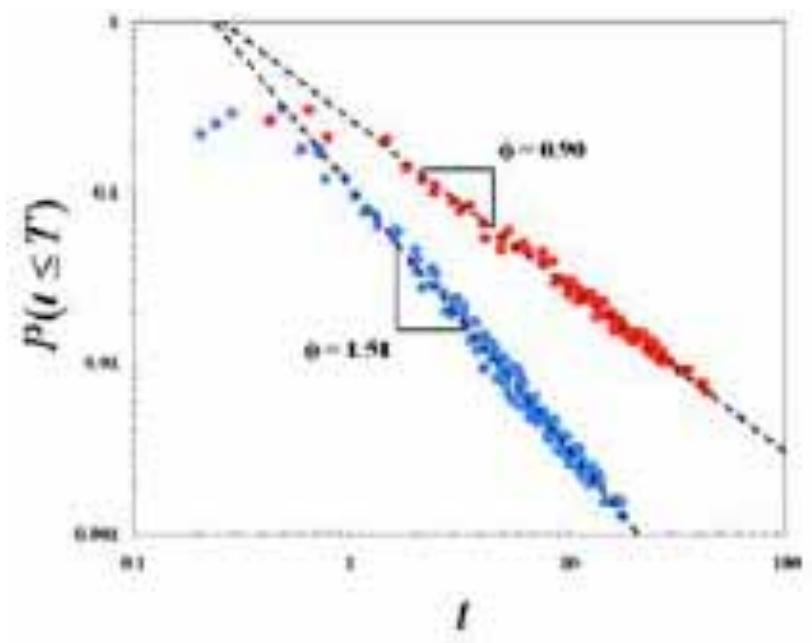

Fig. (2). Cumulative probability distribution function $P(t \leq T)$ shown as a function of move duration $t$ (sec) for uncontaminated control seawater (blue dots) and naphthalene contaminated seawater (red dots).

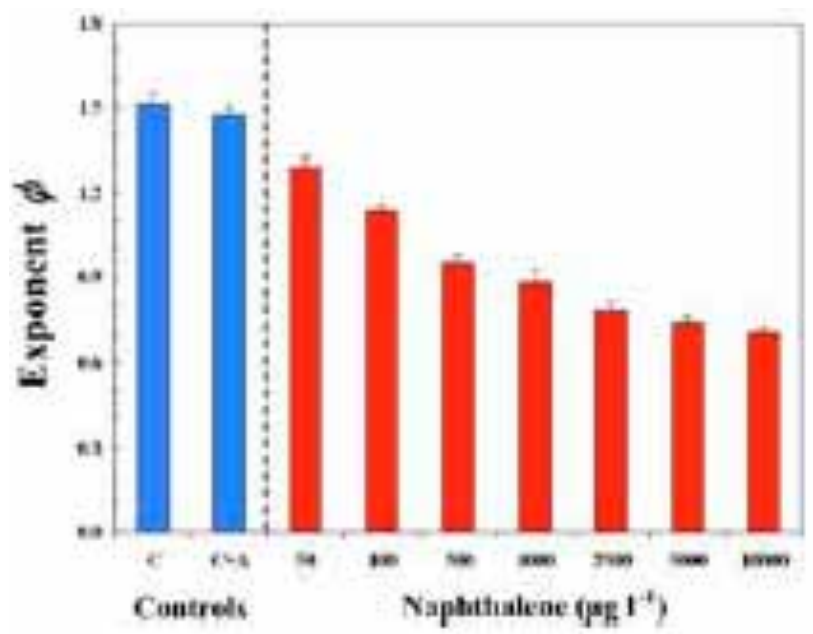

Fig. (3). The stress exponents $\phi$ estimated from the uncontaminated control experiments conducted without $(\mathrm{C})$ and with $(\mathrm{C}+\mathrm{A})$ acetone, and the seawater contaminated with increasing naphthalene concentrations.

In addition, the scaling property of the cumulative probability distribution function of move duration $T(P(t \leq T)=$ $k t^{-\phi}$, see Fig. 3) is indicative of an underlying fractal structure 
in the time series of behavioral sequences. Behavioral time series, though they often appear erratic, reveal 1/f like spectra; i.e., they are fractal-like because they display self-similar (scale invariant) fluctuations over a wide range of time scales [45,57]. Long-range correlation in biological systems is adaptive because it serves as an organizing principle for highly complex, nonlinear processes and it avoids restricting the functional response of an organism to highly periodic behavior [58]. For example, 1/f temporal fluctuations are found in the heart rate of healthy individuals [59], respiratory intervals in animals [60] and neuronal discharges during sleep [61]. The time series of interbeat intervals in healthy subjects have more complex fluctuations than patients with severe cardiac disease [58,62]. Long-range correlations have been also observed in the stride interval of human gait [6364]. From primates to fish, fractal dimension can detect impairments in the behavior sequences of individuals under stress, indicating its value in early stress assessment [45,53$55,65]$.

In summary, fractal-like fluctuations in behavioral sequences reflect changes in environmental conditions. Animals acquire information about the resources in their surroundings by foraging, but this behavior uses metabolic energy and increases the risk of predation. The fractal organization of motion behavior optimizes the cost-benefit as demonstrated by comparing random and fractal search efficiency [66] and explains why locomotor activity does not occur randomly in time, but rather fractal-like [67]. A direct consequence of the observed sharp decay in the behavioral complexity of the copepod $C$. hamatus with increasing naphthalene concentration (Fig. 3) is a likely decrease in their foraging efficiency, hence their ingestion rates. This is consistent with the observed decreased or inhibited feeding [1720], increased mortality [21], reduction in egg production [22], hatching rates [19] and clutch size [23] after exposure to PAHs.

The modifications of $C$. hamatus swimming sequences are also likely to affect the ability to detect potential sexual partners and to modify predation risk. As these modifications were clearly observed even at the lowest concentration tested (see Fig. 3), it is believed that the bottom-up effects of PAH pollutions on the whole planktonic ecosystems may be critical well below lethal concentrations. This is particularly relevant in estuarine, coastal and shelf waters where a variety of localized and obscure anthropogenic pollutions might ultimately be much more harmful for the ecosystem than the massive, though still relatively rare, crude oil spills. While this issue is well beyond the scope of the present work, future studies should thoroughly investigate the potential impact of $\mathrm{PAH}$-induced behavioral modification on the structure and function of the planktonic food chain.

\section{DISRUPTION OF SWIMMING AS AN INDICATOR OF ENVIRONMENTAL CONTAMINATION}

Several behavioral responses have been used to assess toxicant effects on various test organisms, including distance traveled, travel velocity, frequency of direction change, time spent active, response to light and tail-flip escape response [68-69]. Swimming speed is perhaps the most frequently used 'behavioral' measure of an aquatic organism's physiological status [70-71]. In particular, many studies of swim- ming behavior have focused on swimming capacity or ability and forced swimming. However, most of these studies have been made using teleost fish [72-74]. Similar information for aquatic invertebrates is limited.

Mysids have been frequently used in laboratory toxicity tests [75-76] but, despite a large literature on their swimming behavior [77-78], there are only a few published data on the effects of toxicant exposure on mysid swimming. For instance, the swimming ability and orientation of the Neomysis integer were disrupted after 7 day exposure to heavy metals [79] and pesticides [80]. While these results stress the advantages of behavioral toxicity tests for predicting the influence of pollutants and support the use of swimming behavior disruption as a sensitive end-point for detecting pollutant exposure in this species, the duration of pollutant exposure is not compatible with a rapid assessment of any increase in the background concentration of pollutants. Rapid (1 to 3-h) toxicity screening tests with the freshwater flee Daphnia magna using motion analysis systems were reported recently [33-34]. The immobility index $\mathrm{EC}_{50}$ (i.e. the contaminant concentration needed to inhibit swimming activity in $50 \%$ of the test individuals) revealed synergistic, antagonistic, or additive interactions existed between heavy metals and agricultural chemicals [81], while the fractal structure of $D$. magna swimming trajectories was related to the concentration of toxic chemicals and the exposure time [34].

Although acute toxicity tests provide a simple index of contaminant toxicity for regulatory authorities, they provide little information on the effects of toxicants in the natural environment, where concentrations of individual toxic contaminants are generally much lower than the $\mathrm{LC}_{50}$ (median lethal concentration) values estimated in the laboratory [82]. This is not the case for the toxicity assay performed in the present work which is very sensitive to naphthalene contamination, even at very low concentration (Fig. 3). In addition, the results presented here represent the first application of zooplankton behavior to the assessment of marine waters contamination, and improve previous behavior-based approaches in several ways. First, the short exposure time (20 min) allows a quasi-real time assessment of water quality. Second, the method used here to assess behavioral stress is free of the potentially fatal pitfalls identified for behavioral fractal analysis. The limited range of scales available in most behavioral studies can then erroneously lead to identify the result of underlying randomness as a fractal pattern [83-84], while non-fractal models such as Correlated Random Walk models can typically exhibit a fractal signature [85-86] referred to as 'apparent fractality' [87-88]. Finally, it is stressed that contrary to the numerical methods related to fractals and multifractals our approach does not require any specific numerical skills and can conveniently be used to compare the results from other studies using standard statistical tests.

\section{CONCLUSIONS}

The results presented in this study suggest that the change in the complexity of behavioral sequence of freeswimming copepods could be utilized as a sub-lethal stress indicator in toxicity tests and could become a very simple and rapid toxicity screening method. Given the advantages of the experimental simplicity, short exposure time, and low 
concentration for detection, the behavioral analysis introduced here is especially useful for comparing swimming behavior, which could be taken as an endpoint for an acute bioassay. In particular, it is stressed that the measurements of an organism's behavior following contaminant exposure may provide a better understanding of the likely environmental consequences of toxic contamination than lethal effects, especially if behavior is disrupted at environmentally-realistic toxicant concentrations.

The efficiency of the behavioral approach introduced here has been specifically illustrated to investigate the level of stress of copepods exposed to a wide range of naphthalene concentration. It is stressed, however, that this method could conveniently be used to assess relative changes in the behavioral complexity of zooplanktonic organisms in a wide range of ecologically relevant situation related to e.g. the quality and the quantity or food, and the presence of mates and predators. In particular, as previously demonstrated for several fractal and multifractal measure of behavioral [39,89] and environmental [90-91] complexity, the differences between the values of the exponents $\phi$ observed for a given species or environment under stressful and non-stressful conditions might be more informative on the related behavioral changes rather than the absolute values of $\phi$. While the structure of sequential behavior patterns has been successfully applied to assess stress in a variety of terrestrial and aquatic vertebrates [45-46,53-57], further studies are still needed to generalize their use to aquatic invertebrates.

\section{ACKNOWLEDGEMENTS}

The present work has been financially supported by the Centre National de la Recherche Scientifique, the University of Sciences and Technologies of Lille, the Flinders University and the Australian Research Council.

\section{REFERENCES}

[1] Cachot J, Geffart O, Augagneur S, et al. H. Evidence of genotoxicity related to high PAH content of sediments in the upper part of the Seine estuary (Normandy, France). Aquat Toxicol 2006; 79: 257-267.

[2] Fernandes MB, Sicres MA, Boireau A, Tronczynski J. Polyaromatic hydrocarbon $(\mathrm{PAH})$ in the Seine River and its estuary. Mar Pollut Bull 1997; 34: 857-867.

[3] Barbier M, Joly D, Saliot A, Tourres D. Hydrocarbons from sea water. Deep-Sea Res 1973; 20: 305-314.

[4] Witt G. Polycyclic aromatic hydrocarbons in water and sediments of the Baltic Sea. Mar Pollut Bull 1995; 31: 237-248.

[5] Law RJ, Dawes VJ, Woodhead RJ, Matthiessen P. Polycyclic aromatic hydrocarbons (PAH) in seawater around England and Wales. Mar Pollu tull 1997; 34: 306-322.

[6] Doval MD, Moroo A, Pazos Y, et al. Monitoring dissolved aromatic hydrocarbons in Rias Baixas embayments (NW Spain) after Prestige oil spills: relationship with hydrography Est Coast Shelf Sci 2006; 67: 205-218.

[7] Lee WY, Nicol JAC. The effects of the water soluble fractions of no. 2 fuel oil on the survival and behaviour ofcoastal and oceanic zooplankton. Environ Bull 1977; 12: 279-292.

[8] Dahl E, Laake M, Tjessem K, Eberlein K, Boehle B. Effects of Ekofisk crude oil on an enclosed planktonic ecosystem. Mar Ecol Prog Ser 1983; 14: 81-91.

[9] Ostgaard K, Eide I, Jensen A. Exposure of phytoplankton to Ekofish crude oil. Mar Environ Res 1984; 11: 183-200.

[10] Law RJ, Kelly C. The impact of the "Sea Empress" oil spill. Aquat Living Resour 2004; 17: 389-394.

[11] Varela, M. Bode A, Lorenzo J. The effect of the "Prestige" oil spill on the plankton of the N-NW Spanish coast. Mar Pollut Bull 2006; 53: $272-286$.
[12] Goutz HM, Berland B, Leveau M, Bertrand JC. Effects of petroleum biodegradation products on phytoplankton growth. Second International Colloquium on Marine Bacteriologie, pp. 621-627. IFREMER, Paris, France.

[13] Tomajka J. The influence of petroleum hydrocarbons on the primary production of the Danube River plankton. Acta HydrochimieHydrobiologie 1985; 13: 615-618.

[14] Skjøldal HR, Thingstad TF. Oil pollution and plankton dynamics. 4. Summary of enclosure experiments in Lindaaspollene, Norway, with special emphasis on the balance between autotrophic and heterotrophic processes. In: J. Kuiper, W.J. van den Brink Eds. Fate and Effects of Oil in Marine Ecosystems 1987; 159-172.

[15] Samain JF, Moal J, Alayse Danet AM, Daniel JY, Le Coz JR. Model for rapid detection of sub lethal effects of pollutants. 2. An in situ example: Anomalous metabolism of the hyponeustonic copepod Anomaloeem patersoni coinciding with an oil spill. Mar Biol 1981; 64: 35-41.

[16] Samain JF, Moal J, Coum A, Le Coz JR, Daniel JY. Effects of the Amoco Cadiz oil spill on zooplankton. A new possibility of ecophysiological survey. European Marine Biological Symposium on the Protection of Life in the Sea 1980; 33: 225-235.

[17] Berdugo V, Harris RP, O'Hara SC. The effect of petroleum hydrocarbons on reproduction of an estuarine planktonic copepod in laboratory cultures. Mar Pollut Bull 1977; 8: 138-143.

[18] Berman MS, Heinle DR. Modification of the feeding behavior of marine copepods by sub-lethal concentrations of wateraccommodated fuel oil. Mar Biol 1980; 56: 59-64.

[19] Cowles TJ, Remillard JF. Effects of exposure to sublethal concentrations of crude oil on the copepod Centropages hamatus. 1. Feeding and egg production. Mar Biol 1983; 78: 45-51.

[20] Barata C, Baird DJ, Medina M, Albalat A, Soares AMVM. Determining the ecotoxicological mode of action of toxic chemicals in meiobenthic marine organisms: stage specific short tests with Tisbe battagliai. Mar Ecol Prog Ser 2002; 230: 183-194.

[21] Gajbhiye SN, Mustafa S, Mehta P, Nair VR. Assessment of biological characteristics on coastal environment of Murud (Maharashtra) during the oil spill (17 May 1993). Indian J Mar Sci 1995; 24: 196-202.

[22] Ott FS, Harris RP, O'Hara SCM. Acute and sublethal toxicity of naphthalene and three methylated derivatives to the estuarine copepod, Eurytemora affinis. Mar Environ Res 1978; 1: 49-58.

[23] Barata C, Calbet A, Saiz E, Ortiz L, Bayona J. Predicting single and mixture toxicity of petrogenic polycyclic aromatic hydrocarbons to the copepod Oithona davisae. Environ Toxicol Chem 2005; 24: $210-217$

[24] Calbet A, Saiz E, Barata C. Lethal and sublethal effects of naphathalene and 1,2-dimethylnaphtalene on the marine copepod Paracartia grani. Mar Biol 2007; 151: 195-204.

[25] Wade TL, Qhinn JG. Hydrocarbons in the Sargasso Sea surface microlayer. Mar Poll Bull 1975; 6: 54-57.

[26] Offenheimer CH, Gunkel W, Gassmann G, et al. Microorganisms and hydrocarbons in the North Sea during July-August 1975: 1977: Proceedings of the 1977 Oil Spill Conference (Prevention, Behavior, Control, Cleanup); 1977 March; New Orleans, USA.

[27] Pavletic Z, Munjko I, Jardas J, Matoricken I. Quelques observations sur la pollution verticale de la mer par les huiles minérales et les phénols dans l'Adriatique centrale et méridionale faites à l'automne 1971-1972: 1975: Les Journées d'Etudes sur les Pollutions Marines ; 1974 Dec ; Monaco.

[28] Barbier M, Joly D, Saliot A, Tourres D. Hydrocarbons from sea water. Deep-Sea Res 1973; 20: 305-314.

[29] Law RJ, Dawes VJ, Woodhead RJ, Matthiessen P. Polycyclic aromatic hydrocarbons $(\mathrm{PAH})$ in seawater around England and Wales. Mar Pollut Bull 1997; 34: 306-322.

[30] Goodrich MS, Lech JJ. A behavioral screening assay for Daphnia magna: A method to assess the effects of xenobiotics on spatial orientation. Environ Toxicol Chem 1990; 9: 21-30.

[31] Dodson SI, Hanazato T, Gorski PR, et al. Behavioral responses of Daphnia pulex exposed to carbaryl and chaoborus kairomone. Environ Toxicol Chem 1995; 14: 43-50.

[32] Baillieul M, de Wachter B, Blust R, et al. Effect of salinity on the swimming velocity of the water flea Daphnia magna. Physiol Zool 1998; 71: 703-707.

[33] Piao M, Okamura H, Luo R, Aoyama I. Interactive effect of heavy metals and pesticide on Daphnia magna. Jpn. J Environ Toxicol $2000 ; 3: 23-32$. 
[34] Shimizu N, Ogino C, Kawanishi T, Hayashi Y. Fractal analysis of Daphnia motion for acute toxicity bioassay. Environ Toxicol 2002; 17: 441-448.

[35] Bailleul M, Blust R. Analysis of the swimming velocity of cadmium-stressed Daphnia magna. Aquat Toxicol 1999; 44: 245-254.

[36] Burlinson FC, Lawrence AJ. Development and validation of a behavioural assay to measure the tolerance of Hediste diversicolor to copper. Environ Poll 2006; 145: 274-278.

[37] Howlett R. Sex and the single copepod. Nature 1998; 394: 423425.

[38] Woodson CB, Webster DR, Weissburg MJ, Yen J. Response to copepods to physical gradients associated with structure in the ocean. Limnol Oceanogr 2005; 50: 1552-1564.

[39] Seuront L. Effect of salinity on the swimming behaviour of the calanoid copepod Eurytemora affinis. J Plankton Res 2006; 28 : 805-813.

[40] Kiørboe T. Mate finding, mating, and population dynamics in a planktonic copepod Oithona davisae: there are two few males. Limnol Oceanogr 2007; 52: 1511-1522.

[41] Corner EDS, Harris RP, Kilvington CC, O'Hara SCM. Petroleum compounds in the marine food web: short-term experiments on the fate of naphthalene in Calanus. J Mar Biol Assoc UK 1976; 56: 121-133.

[42] Harris RP, Berdugo V, O'Hara SCM, Corner EDS. Accumulation of ${ }^{14} \mathrm{C}$-1-Naphthalene by an oceanic and an estuarine copepod during long-term exposure to low-level concentrations. Mar Biol 1977; 42: $187-195$.

[43] Seuront L, Spilmont N. Self-organized criticality in intertidal microphytobenthos patch patterns. Physica A 2002; 313: 513-539.

[44] Seuront L, Leterme C. Microscale patchiness in microphytobenthos distributions: evidence for a critical state. In: J.C. Kromkamp, J. de Brouwer, GF Blanchard, R.M. Forster, V. Créach Eds. Functioning of microphytobenthos in estuaries. The Academy of Arts and Sciences, Amsterdam/The University of Chicago Press, Chicago; 2006 165-183.

[45] Alados CL, Escós J, Emlen JM. Fractal structure of sequential behaviour patterns: an indicator of stress. Anim Behav 1996; 51: 437-443.

[46] María GA, Escós J, Alados CL. Complexity of behavioural sequences and their relation to stress conditions in chickens (Gallus gallus domesticus): a non-invasive technique to evaluate animal welfare. Appl Anim Behav Sci 2004; 86: 93-104.

[47] Zarr JH. Biostatistical analysis. Prentice Hall, 1996.

[48] Costello JH, Strickler JR, Marrasé C, Trager G, Zeller R, Freise AJ. Grazing in a turbulent environment: behavioral response of a calanoid copepod, Centropages hamatus. Porc Natl Acad Sci USA. 1990; 87: 1648-1652.

[49] Hwang JS, Costello JH, Strickler JR. Copepod grazing in turbulent flow: elevated foraging behavior and habituation to escape responses. J Plankton Res 1994; 16: 421-431.

[50] Parsons PA. Stress-resistance genotypes, metabolic efficiency and interpreting evolutionary change. In: R. Bijlsma, V. Eds. Environmental Stress, Adaptation and Evolution. Birkhäuser Verlag Basel/Switzerland. 1997; 291-305.

[51] Emlen ST, Oring OW. Ecology, sexual selection and the evolution of mating systems. Science 1977; $197: 215-222$.

[52] Wedemeyer GA. Physiology of Fish in Intensive Culture. Chapman and Hall, NY, 1996.

[53] Carlstead K, Brown JL, Straw W. Behavioral and physiological correlates of stress in laboratory cats. Appl Anim Behav Sci 1993; 38: $143-158$.

[54] Escós J, Alados CL, Emlen JM. Fractal structures and fractal functions as disease indicators. Oikos 1995; 74: 310-314.

[55] Alados CL, Weber D. Lead effects on the predictability of reproductive behaviour in fathead minnows (Pimephales promelas): a mathematical model. Environ Toxicol Chem 1999; 18: 2392-2399.

[56] Motohashi Y, Miyazaki Y, Takano T. Assessment of behavioural effects of tetrachloroethylene using a set of time-series analyses. Neurotoxicol. Teratol 1993; 15: 3-10.

[57] Quenette PY, Desportes JP. Temporal and sequential structures of vigilance behaviour of wild boars (Sus scrofa). J Mammal 1992; 73: 535-540.

[58] Buldyrev SV, Goldberger AL, Havlin S, Peng CK, Stanley HE. Fractals in biology and medicine: from DNA to the heartbeat. In: A. Bunde, S. Havlin Eds. Fractal in Science. Springer-Verlag, Berlin 1994; 49-87.
[59] Meesmann M, Boese J, Chialvo DR. Demonstration of 1/f fluctuations and white noise in the human heart rate by the variance-timecurve: implications for self-similarity. Fractals 1993; 1: 312-320.

[60] Kawahara K, Yamauchi Y, Nakazono Y, Miyamoto Y. Spectral analysis on low frequency fluctuation in respiratory rhythm in the decerebrate cat. Biol Cybern 1989; 61: 265-270.

[61] Yamamoto M, Nakahama H, Shima K, et al. Neuronal activities during paradoxical sleep. Adv Neurolog Sci 1986; 30: 1010-1022.

[62] Stanley HE, Buldyrev SV, Goldberger AL, et al. Fractal landscapes in biological systems: long-range correlations in DNA and interbeat heart intervals. Physica A 1992; 191: 1-12.

[63] Hausdorff JM, Peng CK, Ladin Z, Wei JY, Goldberger AL. Is walking a random walk? Evidence for long-range correlations in stride interval of human gait. J Appl Physiol 1995; 78: 349-358.

[64] Hausdorff JM, Mitchell SL, Firtion R, et al . Altered fractal dynamics of gait: reduced stride-interval correlations with aging and Huntington's disease. J Appl Physiol 1997; 82: 262-269.

[65] Alludes CL, Huffman M. Fractal long-range correlation in behavioural sequences of wild chimpanzees: a non-invasive analytical tool for the evaluation of health. Ethnol 2000; 106: 105-116.

[66] Cole BJ. Fractal time in animal behaviour: the movement activity of Drosophila. Anim Behav 1995; 50: 1317-1324.

[67] Martin JR, Ernst R, Heinsenberg M. Temporal pattern of locomotor activity in Drosophila melanogaster. J Comp Physiol 1999; 184: 73-84.

[68] Lang WH, Miller DC, Ritacco PJ, Marcy M. The effects of copper and cadmium on the behaviour and development of barnacle larvae. In: J. Vernberg, A. Calabrese, F.P. Thurburg, W.B. Vernberg Eds. Biological monitoring of marine pollutants. Academic Press, New York; 1981: 165-203.

[69] Sørensen FF, Bayley M, Baatrup E. The effects of sub-lethal dimethoate exposure on the locomotor behaviour of the collembolan Folsomia candida (Isotomidae). Environ Toxicol Chem 1995; 14: 1587-1590.

[70] Bayley and Baatrup. Pesticide uptake and locomotor behaviour in the woodlouse: an experimental study employing video-tracking and ${ }^{14} \mathrm{C}$-labelling. Ecotoxicol 1996; 5: 35-45.

[71] Wilson RW. Physiological and metabolic costs of acclimation to sub-lethal acid and aluminium exposure in rainbow trout. In: E.W. Taylor Ed. Toxicology of aquatic pollution: physiological, cellular and molecular processes. Cambridge University Press, Cambridge, USA. 1996; 143-168.

[72] Wilson RW, Wood CM. Swimming performance, whole body ions and gill Al accumulation during acclimation to sub-lethal aluminium in juvenile rainbow trout (Oncorhynchus mykiss). Fish Physiol Chem 1992; 10: 149-159.

[73] Little EE, Finger SE. Swimming behaviour as an indicator of sublethal toxicity in fish. Env Toxicol Chem 1990; 9: 13-19.

[74] Beaumont MW, Butler PJ, Taylor EW et al. Impairment of sustained swimming performance of brown trout (Salmo trutta) exposed to sub-lethal copper in soft acidic water. J Physiol 1995; 483: 197-198.

[75] USEPA. Short-term methods for estimating the chronic toxicity of effluents and receiving waters to marine andestuarine organisms. EPA 600:4-87-028, Cincinnati, Ohio, 1987.

[76] ASTM. Standard Guide for Conducting Life-Cycle Toxicity Tests with saltwater Mysids. E1191-90. American Society for Testing of Materials, Philadelphia, PA, 1990.

[77] Hough AR, Naylor E. Distribution and position maintenance of the estuarine mysid Neomysis integer. J Mar Assoc UK. 1992; 72: 869876.

[78] Roast SD, Widdows J, Jones MB, et al. The position maintenance behaviour of Neomysis integer (Peracarida: Mysidacea) in response to current velocity, substratum and salinity. J Exp Mar Biol Ecol $1998 ; 220: 25-45$.

[79] Roast SD, Widdows J, Jones MB, et al. Mysids and trace metals: disruption of swimming as a behavioural indicator of environmental contamination. Mar Environ Res 2000; 50: 107-112.

[80] Roast SD, Widdows J, Jones MB, et al. Disruption of swimming in the hyperbenthic mysid Neomysis integer (Peracarida: Mysidacea) by the organophsphate pesticite chlorpyrifos. Aquat Toxicol 2000; 47: 227-241.

[81] Sturn A, Hansen PD. Altered cholinesterase and monooxygenase levels in Daphnia magna and Chironomus riparius exposed to environmental pollutants. Ecotoxicol Environ Safety 1999; 42: 9-15. 
[82] Gaudy R, Guérin JP, Kerambrun P. Sublethal effects of cadmium on respiratory metabolism, nutrition, excretion and hydrolyse activity in Leptomisys lingura (Crustacea: Mysidacea). Mar Biol 1991; 109: 493-501.

[83] Avnir D, Biham O, Lidar D, Malcai O. Is the geometry of nature fractal? Science 1997; 279: 39-40.

[84] Malcai O, Lidar D, Biham O, Avnir D. Scaling range and cutoffs in empirical fractals. Phys Rev E 1998; 56: 2817-2828.

[85] Turchin P. 1996. Fractal analysis of movement: a critique. Ecology 1996; 77: 2086-2090.

[86] Benhamou S. How to reliably estimate the tortuosity of an animal's path: straightness, sinuosity, or fractal dimension? J Theor Biol 2004; 229: 209-220.
[87] Hamburger D, Biham O, Avnir D. Apparent fractality emerging from models of random distributions. Phys Rev E 1996; 53: 33423358

[88] Halley JM, Hartley S, Kallimanis AS, Kunin WE, Lennon JJ, Sgardelis SP. Uses and abuses of fractal methodology in ecology. Ecol Lett 2004; 7: 254-271.

[89] Seuront L, Schmitt FG, Brewer MC, Strickler JR, Souissi S. From random walk to multifractal random walk in zooplankton swimming behavior. Zool Stud 2004; 43: 8-19.

[90] Seuront L, Gentilhomme V, Lagadeuc Y. Small-scale nutrient patches in tidally mixed coastal waters. Mar Ecol Prog Ser 2002; 232: $29-44$.

[91] Seuront L. Hydrodynamical and tidal controls of small-scale phytoplankton patchiness. Mar Ecol Prog Ser 2005; 302: 93-101. 